\title{
1 \\ INTRODUCTION \\ A global trend, an emerging field, a multiplicity of understandings: Science communication in 39 countries
}

\author{
Toss Gascoigne and Bernard Schiele
}

This book is a comprehensive attempt to chart the history of science communication as it developed in the modern era. It tells the story from the perspective of researchers and practitioners in the field, collecting accounts of how modern science communication has developed internationally. The book contains 40 chapters: two introductory chapters, 36 chapters focusing on a single country, ${ }^{1}$ one covering the three Scandinavian countries, and one describing the communication of health issues in a region of Africa. It involves 108 authors. The results are astounding, a unique dataset to be explored and a rich cornucopia of information.

This raises a number of questions: What knowledge can we extract from the data and how can this knowledge be shared? What are the theoretical models (either explicit or implicit) to which authors refer? What approaches have worked best, and in which context, and why? What lessons can be learned from all the experiences the chapters recount? What can we learn from the interaction between scientific knowledge and indigenous knowledge or local knowledge systems; and how can we engage people more directly with science or encourage them to participate in science? What are the best ways to counter irrational beliefs based on religion, superstition, ideology, pseudoscience or anti-science?

1 The word 'country' is used in a broad sense. It may refer to an individual nation, a group of countries or a region. 
Each chapter is an in-depth introduction to a country's issues in its sociohistorical context. By comparing them, we can see connections and similarities and understand the differences and the choices made in particular situations.

Although the movement to foster the development of science culture is universal, it can only develop in the historical, cultural and social contexts of a country. This book presents the reader with a comparative analysis, not merely of quantifiable data (e.g. when the first interactive science centre was established in each country), but also the overarching dynamics at play: the narrative. What matters in each case is less the raw data than the accompanying system of significations and justifications. Most authors have taken pains to describe the sequence of events that led or prevented this or that realisation as well as the main phases, debates and issues that characterised the development of science communication. In other words, this data-rich book will reward a transversal reading that alone allows for an in-depth comparison and analysis.

The data document the different approaches taken to address practical problems: training science communicators, establishing science centres and museums, organising campaigns to lift health outcomes, science festivals and public events, media coverage of science, programs to train scientists how to communicate, and countering superstition and fake news. The chapters will reward a close examination, beyond the scope of these introductory remarks, to pivot these data to tackle cross-cutting issues in science communication, and to identify common themes, recurring challenges and potentially adaptable innovations. This is a task to be expanded in a follow-up book of analysis and comparison.

\section{How the book came to be}

Our book asked authors to complete a timeline for their country and nominate dates when key events took place (such as when the first university courses training science communicators were established). This is how the book began, in 2013. It was then that a simple curiosity about the nature of national experiences spurred the editor of this volume to post a message to the $\mathrm{PCST}^{2}$ email discussion list, inviting people to compile dates of key events in science communication in their country:

2 PCST is the Network for the Public Communication of Science and Technology, an international association of science communicators: www.pcst.co/. 
The proposal is for a discussion on the emergence of science communication in different countries round the world. It would look for similarities and differences ... on matters such as:

- the first university courses training science communicators

- research in science communication - the emergence of $\mathrm{PhD}$ courses

- the formation of organisations and associations for science communicators

- conferences, meetings and publications in this area

- employment opportunities

- the terminology (science popularisation, public understanding of science, vulgarisation, social appropriation of science etc)

Have different countries followed different paths, or have we followed the same broad path and the same timelines? What were the foundation steps - how did it all begin? ... [I] am interested in hearing from people who would like to be involved and can present the history of their own country.

People from 17 countries responded, each completing a timeline of up to 15 dates, and the results were presented at the PCST Conference in Brazil in 2014. Then the project went into hibernation until 2017, when the publication of an account of Ireland's science communication story (Trench, Murphy and Fahy, 2017) and a special issue of JCOM (Massarani, de Castro Moreira and Lewenstein, 2017) rekindled interest. Authors from the 2014 conference were asked if they wanted to expand their timelines into a chapter, and new authors were recruited to fill the gaps. An editorial board was established, a publisher signed up, and guidelines sent out to authors. The project sparked international interest and the original 17 contributing countries grew to 45 expressions of interest. What began as a set of dates in a spreadsheet had grown into full-blown chapters.

There have been earlier efforts to chart science communication. The proceedings of the PCST Conference in Montreal in 1994 featured 27 national accounts, with the 'modest aim' (in the words of the editors) 'to present a status report on the development of scientific and technological culture'. The emphasis was different-more focused on Western countries - and so was the content (not surprising given that the papers were written in the infancy of the internet, and when questions about the deficit model of science communication were just beginning). Despite this, the books taken together-the Montreal proceedings of 1994 When Science Becomes Culture (Schiele, 1994), and this book-represent a continuity. 
It also represents a wider preoccupation to strengthen the visibility of science and technology within society-science communication being only one aspect—and the desire to better measure this visibility. In the same movement are all the surveys conducted to assess the level of science culture of given populations and the indicators developed to this end (Eurobarometer, AAAS, LES, not forgetting national surveys); and the survey of all university-based science communication programs carried out a few years ago by the EU. Sociology has demonstrated that the legitimisation of a domain is linked to its historicisation and it is not surprising to see a growing interest in the history of science communication. This book is part of a wider movement that aims to know and describe the history of the field. We hope its significance will become self-evident, because it gives a voice to the actors of the field in their own specific contexts.

\section{One nagging question}

During the process of commissioning the chapters, authors posed one question: what year did the 'modern era' of science communication begin? There is no simple answer to that question: it varies from country to country.

It is worth mentioning that science communication (then called science vulgarisation or popularisation) boomed in the 19th century. This period continued well into the 20th century and is seen as a golden age of science communication by many researchers. But the modes of science communication developed before World War II (WWII) were disrupted by the conflict. Scientists were not at liberty to communicate freely with the public on the grounds of national security, and after the war structural changes interrupted normal processes.

What distinguishes the post-war period from earlier times is the social driving role played by science and technology: they have become the main vehicle of an ever-accelerating movement of social, cultural and economic change, at a pace matched by the integration of the sciences and the economy. The sustainability of this movement is increasingly predicated on the training of a qualified workforce whose function is to produce new knowledge and new applications, and to acquire the skills to make use of these applications in professional and daily life. It also depends on the ability and willingness of the population to accept and adopt advances in technology. The rapid expansion of higher education during the 1960s is directly linked to this development. 
The evolution of post-war society becomes incomprehensible if we do not take into account this dynamic. The narrative is borne out by successive reports of the Organisation for Economic Co-operation and Development (OECD). First, the reports stressed the fact that national competitiveness is linked to innovation: new knowledge and new applications sustain the pace of economic development. Second, they invited national governments to become key actors by creating ministries of science and technology and adopting science policies. Third, they invited states to mobilise their population through the development of science culture by the implementation of programs to promote and propagate scientific knowledge and scientific thinking. This is why the focus of this book on the post-war period is not arbitrary: it reflects this paradigm change.

The timing of the modern era of science communication varies between countries depending on their situation before WWII and the pace of change after WWII. Authors were asked to select the most appropriate date for their country, 'probably somewhere between 1945 and 1980'. The editorial board certainly recognise there were science museums, media reports and associations of science writers before that time, but the 1970s-1990s marked a step-change: new interactive science centres, new jobs, the opening of courses at universities to meet the demand for a career in science communication, the formation of journals, associations and conferences devoted to science communication and new programs to encourage the public to engage with science.

This period, as confirmed by the analysis following this introduction, can be seen as the moment when science communication asserted itself as a social necessity. It was marked by the formation of a group of social actors engaged in that field, sharing a set of practices and inventing terminologies to describe these practices and recognised as a group committed to communicating science. Over the years a second group has emerged, mostly comprised of scholars and academics whose goal is the study of science communication. These two groups are in constant interaction.

\section{Diversity, optimism, doubt, challenges}

\subsection{Diversity}

The book draws on a cross-section of countries: all continents and all cultures. The diversity is reflected across geographical location, income, religion, population, land area, democracy rating and history. Five contributing chapters are from Africa, seven from the Americas, 11 from Asia and the rest from Europe and Australasia. 
Eleven countries rank outside the top 100 in per capita wealth, with Pakistan, Ghana and Uganda ranking the lowest. ${ }^{3}$ Problems, attitudes and actions can be sharply magnified by huge disparities in wealth. There is a factor of 127 separating the richest country involved in the book from the poorest: the median figure for gross domestic product per capita for the 39 countries is US $\$ 22,928,{ }^{4}$ but national figures range from US $\$ 643$ for Uganda to US $\$ 81,807$ for Norway. This has significant implications in defining the issues countries face and where science communication would be part of the solution. It also has implications for their abilities to fund appropriate actions.

Five of the countries represented are Muslim-majority: Nigeria, Iran, Pakistan, Turkey and Malaysia. Twenty-five are Christian-majority; four have a majority of people declaring themselves 'unaffiliated'; two are Buddhist; one Hindu; and one each folk religion and Judaism ${ }^{5}$. Religious attitudes can shape and influence national policies on research and practice in science, with consequent implications for science communication.

Population and land area are two other variables showing great diversity in participating countries. Countries range in population from 1.3 million (Estonia) to 1.4 billion (China), a factor of over 1,000. Nine have a population of below 10 million, balanced by 10 countries with a population above 100 million. The median is 46 million. ${ }^{6}$ National land areas vary from 709 square kilometres (Singapore) to over 16 million (Russia). ${ }^{7}$

Contributing countries also range widely when listed according to the Economist's Democracy Index. Twelve countries are assessed as 'full democracies'; 19 as 'flawed democracies'; 12 as 'hybrid regimes'; and three as 'authoritarian'. The Economist explains its approach as follows:

The index rates 167 countries by 60 indicators across five broad categories: electoral process and pluralism, the functioning of government, political participation, democratic political culture and civil liberties. It is stricter than most similar indices: it concludes that just $4.5 \%$ of the world's people live in a 'full democracy'. ${ }^{8}$

3 GDP per capita 2018 from data.worldbank.org/indicator/ny.gdp.pcap.cd.

4 Again, see GDP per capita 2018 from data.worldbank.org/indicator/ny.gdp.pcap.cd.

5 Pew Research Centre from www.pewforum.org/2015/04/02/religious-projection-table/2020/ percent/all.

6 Populations 2018 from data.worldbank.org/indicator/SP.POP.TOTL?view=chart.

7 Land areas from data.worldbank.org/indicator/AG.LND.TOTL.K2.

8 See www.economist.com/graphic-detail/2019/01/08/the-retreat-of-global-democracy-stoppedin-2018. 
The book documents the way science communication has evolved and the motivations behind its development. The 38 chapters record an astounding variety of science communication modes of mediation, from drumming around the village, to traditional and social media, science cafés and festivals, and meetings with politicians. The approaches vary widely: while Germany relied on traditional media and focused its efforts in training journalists, Russia concentrated on publications and public lectures (in 1990 the Russian science journal Argumenty i Fakty was cited in the Guinness Book of Records as the highest weekly circulation newspaper in the world). South Korea took a whole-of-government approach that lifted the country sharply up international wealth rankings.

The science communication approaches and practices recorded for some participating countries have never been described before. But science communication is not an autonomous field. The actors always have to work and modify their work and discourse according to the context, the plays of power and the social, economic and political imperatives that constitute their environment. Thailand, for instance, was led by King Mongkut, a passionate amateur astronomer and a supporter of science communication who won great respect in his country for successfully predicting an eclipse of the sun two years before it happened in 1868 (he also provided the central character in the musical The King and I, a part played on Broadway and the movie by Yul Brynner).

Brazil celebrated science in the lyrics of the samba Ciência e arte (Science and Art) and Aotearoa New Zealand is marrying indigenous knowledge with Western science. Islamic countries have principles of Shariah (Islamic law) to consider, bearing in mind the twin tenets of halal (permissibility) and haram (forbidden) in shaping science communication activities. Nigeria tells the story of a significant science communication challenge, when a campaign to rid the country of polio was subject to an Islamic fatwa in 2003 because the Muslim community suspected it was part of a plot to sterilise children living in the northern (Muslim) parts of the country. It was only after five leaders of this community visited Egypt to witness a successful campaign that the program was allowed to continue.

\subsection{Optimism}

If before WWII science communication was essentially left to the discretion of scientists and enthusiasts, from the 1970s governments began to assert their role, spurred by the direct impact of science and technology on society. Since then, governments have often led moves in support of modern science communication, investing in interactive science centres, university training 
and public events like national science week. The British story is an example, well-documented through official reports and inquiries. So are the French and Quebec (Canada) stories. But governments with a consistent record are rare: despite public expressions of support for science communication, budgets demonstrate it is often low on the list of governmental priorities, through indifference, competition for funding, lack of commitment despite promises of support repeatedly reaffirmed, or because governments are overwhelmed by other issues.

In some countries, governments have taken a passive role and allowed external institutions and individuals to make the running. In the 1970s the German government stood back, perhaps recalling the unsavoury relationship between Nazi propaganda and science, and private foundations took the lead in funding ambitious programs to train science journalists. In the US, the absence of a strong central agency encouraged many institutions, funding bodies and societies to enter a field described variously as 'vibrant', 'jostling' and 'cacophonous' and characterised by a lack of coordination and centralisation. Reflecting this, the US authors subtitled their chapter 'It's Complicated'.

At times through history, governments have been hostile to attempts to communicate science. The fascist regimes of Italy, Spain and Portugal: the attempts of the Canadian government in 2010 to muzzle scientists on climate change, a coup d'état in Argentina that had 'devastating' effects on science, and state control and censorship in South Africa over the apartheid years- to mention some-all discouraged communication. In all cases the role of the State was a determining factor.

But generally, governments became more interested in science and science communication following WWII, when there was a growing belief in the power of science to unlock a bright new future. Governments had seen what science could do in the war years. In 1945 US President Franklin D. Roosevelt asked Vannevar Bush, Director of the US Office of Scientific Research and Development, a simple question: we have seen what science can do for us in war, but what can science do in times of peace?

Bush's response, Science: The Endless Frontier (1945), set out a vision for science in modern life:

Advances in science when put to practical use mean more jobs, higher wages, shorter hours, more abundant crops, more leisure for recreation, for study ... Advances in science will also bring higher standards of living, will lead to the prevention or cure of diseases, will promote conservation of our limited national resources, and will assure means of defense against aggression. 
Bush's optimism was picked up by the leaders of newly independent states in Africa and Asia, and voiced by Kwame Nkrumah, prime minister of Ghana. In an address to the first conference of the Organisation of African Unity (OAU) in 1963, Nkrumah said:

We shall accumulate machinery and establish steel works, iron foundries and factories; we shall link the various States of our continent with communications; we shall astound the world with our hydroelectric power; we shall drain marshes and swamps, clear infested areas, feed the under-nourished, and rid our people of parasites and disease. It is within the possibility of science and technology to make even the Sahara bloom into a vast field with verdant vegetation for agricultural and industrial developments. We shall harness the radio, television, giant printing presses to lift our people from the dark recesses of illiteracy ... The world is no longer moving through bush paths or on camels and donkeys.

The visions outlined by Bush and Nkrumah could only be realised if the mindset of the people was aligned to science. This was a monumental task for science communication: changing long-held beliefs and attitudes, opening the eyes of people to the possibilities of better approaches to health, agriculture and industrialisation, and preparing people for a new future. Implicit in this was the need for public acceptance, awareness and education.

Further impetus came in the 1960s. Beginning in 1963, the OECD had a central presence in asserting the fundamental role of the sciences and technologies in modern societies and insisting on the necessity for governments to develop science policies to sustain economic growth. Governments responded by establishing ministries for science and developing science policies. The second report in 1971 took a broader view of science, putting forward its social and cultural aspects. It is from that moment that science communication entered the political discourse (Piganiol et al., 1963; Brooks et al., 1971; OECD, 1981). The vision promoted by the OECD, with the exception of the United States, was quickly adopted by countries that were not members of the organisation (Henriques and Larédo, 2012).

\subsection{Doubt}

Eighteen countries participating in the book have a colonial history at some time in the 20th century. To that number must be added the countries in East Africa covered by the chapter on African health. This history has helped shape opportunities and attitudes to science communication.

The Nkrumah quotation above was typical of how eagerly former colonies anticipated independence and the freedom to invest in the future of their countries. Plans were formulated and optimism was strong in the newly 
independent countries. A lot was depending on science communication and the role it would play in changing attitudes, educating the people and modifying behaviours. But post-independence progress took time, interrupted by competing priorities, inexperience in government, inadequate resources, regional and personal conflicts and being weighed down by having to deal with immediate issues rather than the longer-term nature of investments in science. Chapters across all regions record the disappointments as well as the successes, and many authors report programs in science communication that began with enthusiasm but failed to deliver.

Faltering progress was not limited to the former colonies. Ireland has planned and lobbied for a science centre for 30 years and $€ 13$ million is still needed to complete the project. South African efforts to create a scientifically literate society are documented in the book as being hampered by inexperience and misguided politics, and the intricacies of balancing indigenous knowledge systems with modern science. In Turkey, the committee responsible for implementing the first official policy on science (and science communication) has failed to meet for many years. Mexico reports weak systems to incorporate science into the general culture of the population through collaboration and evaluation; Taiwan describes poor-quality coverage of science by mainstream media; Canada that the development of science culture has ceased to be the priority it once was; Pakistan awaits the necessary framework to communicate science to its public effectively; and Italy concludes that incentives for scientists to communicate their work are poor. Australia commissioned an inquiry into science communication in 2011 and funded national activities, but this has faded over time under a conservative government. These problems, shortcomings and issues are shared by other countries.

In addition to economic considerations, other social and cultural factors were involved. In the decades immediately after WWII, optimism was dominant in the era of Big Science, and the positive image of science reflected on scientists. Their influence was so great that although they were not in power, we could speak of a parliament of science. But although optimism was predominant (Sputnik, transistor radios, antibiotics and non-stick frying pans), doubts about the role of science and the effects of progress were emerging. Hiroshima cast a long shadow and concerns about the environment grew. Public opinion began to turn through the 1960s and 1970s. On the one hand, social movements (in Europe, the US and elsewhere), not least the peace movement, challenged authoritarianism and militarism. The continuing development of nuclear weapons was controversial, and the image of scientists was stained with the condemnation of their involvement. Environmental crises, such as the 1967 sinking of the Torrey Canyon, led to a growing awareness of the negative impacts of progress. 
With the idea of progress being increasingly questioned (particularly in developed countries), the concept of risk entered collective consciousness and an ambivalence towards the development of the sciences and technologies led the UK's House of Lords to declare in 2000 that 'society's relationship with science is in a critical phase'.

\subsection{Challenges}

The authors have identified a number of challenges that science communication faces: fear of change, indifference, scepticism, superstition, competition for funding and resources, and cultural or religious differences. They report different experiences of a collision between 'white man's science' and indigenous knowledge: some countries have made significant progress towards resolving these issues, while others still wrestle with them. The 'system' can also work against science communication. Despite a broad expectation that scientists will discuss their work and engage with society (the 'third mission'), authors reported limited interest by institutions, funding bodies and governments in rewarding communication work. Like other parts of Europe, Italy is struggling to realise the ambitions of those advocating 'third mission' activities (broadly, 'knowledge-making and engagement with society') and extending them more generally. Scientists have busy lives and if there are no incentives to communicate, it becomes a low priority. They also can become discouraged when their communication efforts have little apparent influence on policy-scientists can be slow to realise that the kind of reliable knowledge they produce is only part of what contributes to a whole society, and that culture, economics and politics play their part in the decision-making process as well.

\section{4. 'Science communication': Terminology and interpretation}

In the course of compiling the chapters, we found that the term 'science communication' has many definitions and not all researchers or practitioners agree on its goals and boundaries. It has been variously described as an objective, goals, a process, a result and an outcome. This confusion over a definition is reflected in the terminology used internationally for the field. From the second half of the 20th century, what we have chosen to call 'science communication' for this book has flown under different headings: 'science popularisation, 'public understanding', 'vulgarisation', 'social appropriation of science and technology', 'public understanding of science' and 'scientific temper' for example. In all, the chapters mention 24 separate terms for the expression 'science communication' that we chose. We have taken note of that variety. 
Most authors, consciously or unconsciously, did not define what they were writing about. Only five chapters included a definition: the US, China, Colombia, Denmark and Uganda. This suggests that an examination of the terms listed above, their evolution and an exploration of their specific meanings presents an opportunity for further research. Do the terms mean the same thing? How has usage changed over time? There appears to be no agreement on a commonly accepted definition, although a consensus is developing across the field generally that in science communication we are talking about a young transdisciplinary field, still developing and evolving, but not yet regarded as a discipline. The multiplicity of appellations implies that the field is not fixed and nor are its practices.

This observation is valid for all countries, regardless of the attempts by a number of researchers to circumscribe science communication as a field of practices and to apprehend individual practices as singular research objects. The heterogeneity of practices implies the heterogeneity of the field, and it is this heterogeneity that has led to the wide variety of terms being used for 'science communication'. In other words, the practices and discourses grouped under various different terms in different countries are the result more of the consensus of actors at a given time rather than of a genuine attempt at the objectification of these practices and discourses. One can wonder if such an objectification is feasible or even desirable.

What we can conclude from the chapters is that 'science communication' (by whatever term) is used to inform, engage, persuade, change behaviours and support better decision-making. Science communication aims to lift the social, environmental and economic standing of a nation's people. Authors report that science communication revolves around problems in diverse regional and cultural contexts: health, economic opportunity and jobs, urban resiliency, food and agriculture, clean energy, managing the development of new technologies and innovation. It may also support the participation of citizens in setting the agenda for scientific research, a democratic motivation. Italy has recently adopted initiatives to actively involve citizens and civil society organisations and develop a public debate'.

\section{Timelines}

There is a timeline at the end of every country's chapter showing key dates for that country. There is also a series of graphs and tables in the chapter following the introduction, amalgamating the national data and allowing an international comparison of (for instance) the date of the first interactive science centre or the first university courses in science communication. The 
collected dates give an indication as to how the field has progressed-as an academic field, as a domain of practices, as a field of practitioners and a subfield of the media.

A word of caution on the timelines. They are indicative rather than precise and show broad directions in an ecosystem of science communication. They should be regarded as markers rather than as definitive, a start to collecting meaningful episodes in the development of science communication. We realise that in some or even many cases, these records will not be the right episodes to explain the story of the development of science communication. The choice of indicators is not arbitrary although they include a degree of uncertainty. These four great generic domains are interlinked insofar as any social organisation is constituted of actors, practices and modes of communication and interaction. They should be objects of scepticism and question, not intended as a definitive account of 'the way things unfolded'. In short, they are a beginning, perhaps a controversial one, not an end.

The timelines have also posed practical difficulties, for a multitude of reasons. It was hard to identify 'firsts' because organisations changed their names, or events like science festivals stopped and started again, or regional events became national. Even the definition of what might be called a science 'festival' or a science communication degree is not always clear. People who became notable science communicators may have done their $\mathrm{PhDs}$ in a related area like science journalism, and what are now full courses in science communication may have begun as semester-length programs or in a different faculty. Nor are the editors or authors historians, but we do have a good grasp of the field and its evolution.

This book marks a milestone. It documents modern practice, the theories that underpin it and explains how countries have reached the position they are in today. For many participants in science communication, progress will appear to have been haphazard, characterised by interruptions, funding crises and the absence of clear and consistent policy. Recording these national stories will bring some sense of order to the process. What we have done is already useful, but it is only by a close examination and interrogation of the chapters themselves that the full value of the work of the authors will be realised.

We need to extract the lessons from the book. The questions listed at the beginning of this introduction are a starting point for the interrogation of what has been called 'a rich cornucopia of knowledge'. Understanding where we have come from and why we are here can only help the field in which we work. Our next task is to plan for an examination and interpretation of the content of the chapters. 
We encourage readers to explore the book and consider the different cultural context within which each chapter was written.

\section{References}

Brooks, H., Adams, J. B., Colombo, U., Crozier, M., Kaysen, C., Kristensen, T., Okita, S., Weizåcker, C. F., Spaey, J., King, A. and Salomon, J.-J. (1971). Science Growth and Society: A New Perspective. Paris: OECD.

Bush, V. (1945). Science: The Endless Frontier. Washington DC: United States Government Printing Office.

Henriques, L. and Larédo, P. (2012). Policy-making in science policy: The 'OECD model' unveiled. Research Policy, 42(3), 801-816. dx.doi.org/10.1016/j.respol. 2012.09.004.

Massarani, L., de Castro Moreira, I. and Lewenstein, B. (2017). A historical kaleidoscope of public communication of science and technology. Journal of Science Communication, 16(3), E. doi.org/10.22323/2.16030501.

Nkrumah, K. (1963, 25 May). Speech to the first conference of the Organisation of African Unity (OAU). Addis Ababa, Ethiopia.

OECD. (1981). La politique scientifique et technologique pour les années 80. Paris: OECD.

Piganiol, P., Herz, K., Major, R., Ramsey, N. F., Schmidt, E. I., Schultz, T. W. and Steacie, E. W. R., (1963). Science and the Policies of Governments - The Implications of Science and Technology for National and International Affairs. Paris: OECD.

Schiele, B. (1994). When Science Becomes Culture. World Survey of Scientific Culture. Éditions MultiMondes and University of Ottawa Press.

Trench, B., Murphy, P. and Fahy, D. (eds). (2017). Little Country, Big Talk: Science Communication in Ireland. UK: Pantaneto Press.

UK House of Lords. (2000). Third Report: Science and Society. Select Committee on Science and Technology.

\section{Contributors}

Toss Gascoigne is a visiting fellow at the Centre for Public Awareness of Science at The Australian National University, Canberra, Australia.

Bernard Schiele is a researcher at the Interuniversity Research Centre on Science and Technology, and Professor of Communication at the Faculty of Communication at the University of Quebec, Montreal, Canada. 